\title{
Cerebral Multimorbidity in Aging
}

\section{Kurt A. Jellinger}

Institute of Clinical Neurobiology, Vienna, Austria

\section{Article Info}

\section{Article Notes}

Received: 29/02/2016

Accepted: 18/03/2016

\section{Keywords}

Alzheimer disease

Cerebral multi-morbidity

Neurodegenerative disease

Proteinopathies

Cerebrovascular lesions

Mixed pathology

\section{${ }^{*}$ Correspondence:}

Kurt Jellinger

Institute of Clinical Neurobiology

Vienna, Austria

Phone \& Fax: +43-1-5266534

E-mail: kurt.jellinger@univie.ac.at

(c) 2016 Jellinger $\mathrm{K}$. This article is distributed under the terms of the Creative Commons Attribution 4.0 International License

\begin{abstract}
The aging brain is characterized by the simultaneous presence of multiple pathologies, and the prevalence of multi-morbidity increases with age. Large clinico-pathological correlative studies have shown that in brains of both cognitively intact and impaired aged subjects, the presence of a single disease is a rare finding, while most brains show neurodegenerative, cerebrovascular and other pathologies, which frequently have been missed clinically and may even be difficult to identify at postmortem examination. Since both clinical and autopsy studies differ in selection and classification criteria and in the applied evaluation methods, irrespective of the clinical symptoms, the reported frequency of cerebral pathologies varies considerably. The frequent co-occurrence of different pathologies indicates their mutual interaction in order to promote cognitive decline and other clinical symptoms. These facts have also implications for improvement of clinical diagnosis and prognosis, for the development of specific biomarkers, preventive strategies, and therapeutic targets for cerebral multi-morbidity.
\end{abstract}


Due to increased life expectancy, understanding of age-associated disorders including cognitive decline is becoming more and more important, since the prevalence and incidence of dementia increase exponentially with age. Worldwide, the prevalence of dementia is projected to increase from about 46.8 million in 2015 to 135 million in $2050^{1}$. Most of the estimated increases in prevalence are predicted to occur in low-income countries, for which adequate funding to invest in dementia research is urgently needed in order to tackle this major public health and socio-economic problem that threatens to become the scourge of our century ${ }^{2}$.

There aremanycauses of cognitiveimpairmentand other age-related neurological symptoms. Although Alzheimer disease (AD) and other neurodegenerative disorders that are caused by deposition of misfolded proteins (proteinopathies) are most prevalent in aged people, about two-thirds of aged human brains contain substantial nonAlzheimer pathology ${ }^{3-5}$. Cognitively intact elderlies may show substantial AD-related pathology, while in the oldestold group (age $80+$ years) ${ }^{6,7}$, much of cognitive decline may not be due to common neurodegenerative pathologies ${ }^{8,9}$ but to multiple pathologies ${ }^{10}$. Co-occurrence of $\mathrm{AD}$ and non-AD type proteinopathies or other superimposed pathologies, in particular cerebrovascular lesions, are frequently occurring in the brains of both cognitively unimpaired and impaired aged individuals, whereas the presence of a single disease is rather the exception than the rule ${ }^{11-14}$. Multiple pathologies are suggested to interact in promoting cognitive and other clinical symptoms in the aged ${ }^{5,14,15}$. AD, in particular, often presents with comorbid processes, including cerebrovascular disease, Lewy body (LB) pathology, argyrophilic grain disease (AGD), transactivation response DNA binding protein 43 (TDP-43), hippocampal sclerosis, and other non-AD pathologies ${ }^{5,14,16-18}$. Many of these lesions may have been missed clinically despite modern diagnostic criteria ${ }^{19}$ and could not be identified at postmortem examination without modern morphological and molecular-biological analyses using revised guidelines for the neuropathological diagnosis of major brain diseases ${ }^{20-22}$.

\section{Neurodegenerative disorders}

The frequency of neurodegenerative lesions in different studies has been summarized recently ${ }^{5}$. ADrelated pathology, previously suggested to be the most frequent type of cerebral lesions in the elderly, according to the statistical evaluation of 12 community-based studies, based on Braak, CERAD and NIA criteria, ranged from 19 to 67\%, while in other studies AD pathology occurred between 42 and $100 \%{ }^{23}$. The disparate results are due to different methods of evaluation, variable age, and differences in cardiovascular and other risk factors (diabetes mellitus, hypertension, atrial fibrillation, etc) ${ }^{5,14}$.
The frequency of "pure" AD corresponding to Braak neuritic stages $\mathrm{V}$ and VI without essential concomitant pathologies, ranged from 12 to $72 \%$ but was only $41 \%$ in a consecutive hospital-based autopsy series of 1,700 elderly demented patients $^{24}$. There are several subtypes of AD that differ in clinical presentation, neuroimaging and distribution of tau pathology ${ }^{25-27}$, which, however, would not have been identified by only semi-quantitative methods ${ }^{17}$. The second most common neurodegenerative disorder is characterized by Lewy ( $\alpha$-synuclein) pathology with a range between 6 and 39\%, but its evaluation depending on the use of immunohistochemistry and classification criteria of LB disorders varied considerably ${ }^{28}$. A combination of $\mathrm{AD}$ pathology with Lewy pathology was seen in 9 to $28 \%$. In DLB, that is characterized by $\alpha$-synuclein pathology, $A \beta$ pathology was found in $95 \%$, considerable tau pathology in $55 \%$, various degrees of cerebrovascular pathology in 75\%, and co-localization between hyperphosphorylated tau and $\alpha$-synuclein was observed ${ }^{29}$. However, both the amount and the topographical distribution of pathological protein aggregates (fibrillary tangles vs. LBs) differ between distinct clinical phenotypes ${ }^{30}$. Moreover, the presence of LBs in clinically healthy elders, referred to as incidental Lewy body disease (iLBD) and suggested as a precursor/preclinical form of Parkinson disease (PD), lacks pathological symptoms due to a sub-threshold pathology ${ }^{31}$. The clinical presentation of other neurodegenerative diseases, such as multiple system atrophy (MSA), progressive supranuclear palsy (PSP), frontotemporal lobar degeneration (FTLD), Pick disease, etc. that have been reported in a subset of elderly subjects (usually below 5-10\%) varies in relation to concomitant pathologies ${ }^{32}$.

\section{Vascular pathologies}

Cerebrovascular pathologies have been reported in 50$85 \%$ of elderly subjects, but due to lack of clearly defined assessment criteria $^{33}$, they show a large range of frequencies. Their spectrum ranges from large cerebral infarcts due to large vesseldisease (multi-infarctencephalopathy) to cortical microinfarcts, subcortical lacunes, microhemorrhages and white matter lesions due to cerebral small vessel disease $(\mathrm{SVD})^{34-36}$. A recent study indicated that in $\mathrm{AD}$ patients the presence of white matter hyperintensities is associated to the severity of cortical tau load rather than to SVD ${ }^{37}$. Subcortical lacunes and microinfarcts appear to be the most common features of cognitive impairment, but may not be associated with an increased burden of AD pathology ${ }^{38}$. Recent emphasis on co-morbidity of $\mathrm{AD}$ and cerebrovascular pathology observed in 30-60\% of aged brains indicates an association between both types of lesions, but their relative impact is under discussion ${ }^{18,39}$. In cases with subclinical AD, critically located vascular lesions or cortical microinfarcts can worsen cognitive impairment due to a synergistic interaction between both pathologies, while in advanced 
or full-blown stages of $\mathrm{AD}$, concomitant small vascular lesions may not significantly influence the progression of cognitive decline that is essentially related to the severity and extent of $\mathrm{AD}$ pathology ${ }^{39,40}$. In general, both vascular and AD-type pathologies are considered to be independent of each other, but may have additive or synergistic effect ${ }^{8,40}$. Cerebrovascular disease as a common finding in aged brains is more common in $\mathrm{AD}$ than in other neurodegenerative disorders and lowers the threshold for dementia due to $\mathrm{AD}$ or synuclein pathologies ${ }^{41}$. These and other data suggest that cerebrovascular disease and $\mathrm{AD}$ are interrelated and that common etiological and reciprocally synergistic pathophysiological mechanisms promote both vascular and AD-related pathologies ${ }^{42}$. "Pure" vascular dementia/ cognitive impairment without additional lesions is rare, for example $12.3 \%$ decreasing prevalence in the oldest old population ${ }^{43}$.

\section{Mixed pathologies}

Although no standardized criteria for mixed dementia are currently available, this neuropathological diagnosis can be made if more than one disease or type of lesions is detected at postmortem examination ${ }^{44}$. The most frequent form is the simultaneous presence of both $\mathrm{AD}$ and cerebrovascular lesions or any other pathology such as LB pathology, AGD, or hippocampal sclerosis. Depending on the definition of mixed dementia/pathologies, its prevalence ranges from 10 to $93 \%{ }^{14}$ and increases with age ${ }^{13,14,45}$. Many studies emphasized multiple pathologies in non-demented elderly subjects, although the burden of brain lesions and co-morbidities varied widely within and across studies ${ }^{46,47}$. However, most of these lesions did not increase the probability of the co-occurrence of other lesions, while the number of coincidental pathologies correlated significantly with AD-related changes-both increasing due to brain aging ${ }^{23}$.

The high prevalence of multiple pathologies in the aged brain reflects the simultaneous presence of a distinct neurodegenerative disease and of age-related changes that are not directly associated but may influence each other ${ }^{10}$. The high prevalence of cerebrovascular lesions in aged brains mirrors the frequency of vascular disease in elderly subjects but does not preclude the possibility that vascular lesions may lower the threshold for overt clinical dementia ${ }^{39}$. Simultaneous presence of a neurodegenerative disease with age-associated brain changes may be documented by the co-occurrence of $\mathrm{AD}$ pathology in Lewy body disorders, including co-localization of $\alpha$-synuclein and tau epitopes in LBs and in neurons of the amygdaloid nucleus ${ }^{48}$. This suggests that $\mathrm{LB}$ formation is triggered, at least in part, by $\mathrm{AD}$ pathology, although recent analyses of mixed AD/DLB cases showed differences in both the amount and topographical distribution of pathological aggregates among the clinical subtypes $^{30}$.The high prevalence of mixed pathologies supports the notion that a combination of cerebral lesions often has a cumulative effect and, if reaching the individual threshold for cognitive impairment, manifests as clinical dementia ${ }^{23,49}$. It should be emphasized that for the concept of multi-morbidity of the aging brain, both AD-related and non-AD- pathologies should be evaluated in detail in order to elucidate their clinical impact ${ }^{32,50}$. For instance, the clinical relevance and quantification of deep white matter lesions is controversially discussed and, since routine histological assessment may underrate subcortical pathology, application of postmortem MRI was recommended as a tool for their detection ${ }^{51}$.

\section{Conclusion and future perspectives}

Currently, the diagnosis of the most important brain diseases is based on semiquantitative scoring of the neuropathological hallmarks, eg., neurofibrillary tangles, amyloid and neuritic plaques, LBs, TDP-43 and other protein inclusions, microinfarcts, microbleeds, white matter lesions, neuronal loss or gliosis, the criteria for most of which have recently been standardized ${ }^{20,33,52}$. New methods are currently being developed which enable high-throughput quantitative assessment of pathological lesions that will enable the identification of new clinico-pathological phenotypes and reflect cerebral multi-morbidity of the aging brain. These methods of automated quantitative assessment, used in routine neuropathological diagnosis, provide a rough estimation of the amount of pathologies present in the brain. However, due to considerable overlap, these changes may fail to distinguish between cognitively intact subjects from those with preclinical disorders ${ }^{53,54}$. Additional challenges arise from the frequent coexistence of various pathologies in the aging brain which may have additive or synergistic effects (Figure 1) ${ }^{55}$. These interactions between pathological

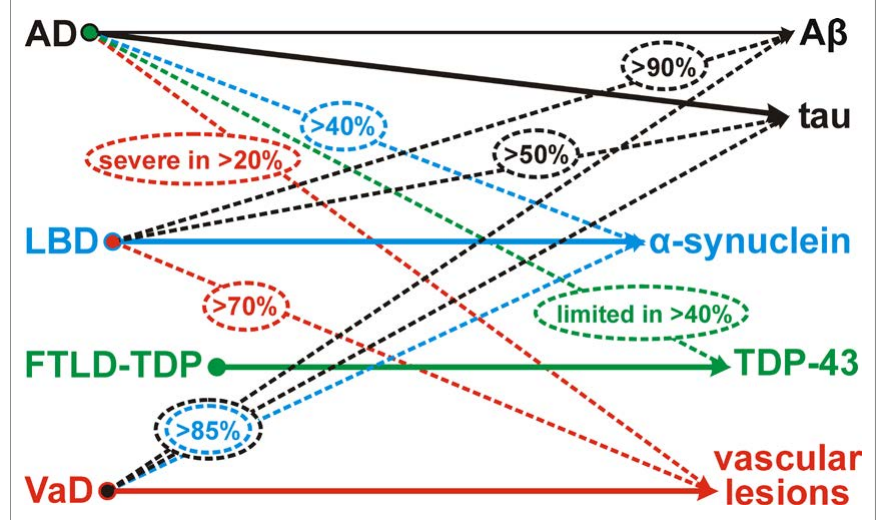

Figure 1: Multiple pathologies in the aging brain. Full arrows point towards the characteristic neuropathology of the respective disease, while dotted arrows point towards neuropathological lesions that are frequently seen in addition to the main pathological hallmark lesions. Approximate percentages are encircled. $A D$ Alzheimer's disease, $L B D$ Lewy body diseases, FTLDTDP frontotemporal lobar degeneration with TDP-43 pathology, VaD vascular dementia. dementia ${ }^{55}$. 
proteins in accelerating neuropathology and cognitive decline due to overlap between synucleinopathies, tauopathies and other proteinopathies have been summarized recently ${ }^{14,56,57}$. Community-based studies have shown that complex constellations of underlying pathologies may lead to cognitive decline and other clinical symptoms the prevalence of which increases with age. The role of cardiovascular and other risk factors for the development of AD-related and mixed cerebral pathologies and their clinical relevance need further elucidation. It is hoped that future studies will identify specific clinical signs or biomarkers that more specifically point toward underlying pathologies with respect to both their quality and quantity. Harmonized studies using modern molecularpathological and quantitative methods are warranted to allow an accurate stratification of patients in view of the freqent co-occurrence of multiple different pathologies and to elucidate possible interaction between different pathological processes in the aging brain as a basis for future neuroprotection and successful treatment.

\section{Conflicts of interests}

The author has no potential conflicts of interests to disclose.

\section{Acknowledgements}

The study was supported in part by the Society for the Promotion of Research in Experimental Neurology, Vienna, Austria. The author thanks Mr. E. Mitter-Ferstl, PhD, for secretarial and computer work.

\section{References}

1. Prince M, Bryce R, Albanese E, Wimo A, Ribeiro W, Ferri CP. The global prevalence of dementia: a systematic review and metaanalysis. Alzheimers Dement. 2013; 9:63-75.

2. The Lancet N. Great expectations for dementia research. Lancet Neurol. 2016.

3. Nelson PT, Jicha GA, Schmitt FA, Liu H, Davis DG, Mendiondo MS, et al. Clinicopathologic correlations in a large Alzheimer disease center autopsy cohort: neuritic plaques and neurofibrillary tangles "do count" when staging disease severity. J Neuropathol Exp Neurol. 2007; 66:1136-1146.

4. Jellinger KA. Neuropathology of dementia disorders. J Alzheimers Dis Parkinsonism. 2014; 4:1-17.

5. Rahimi J, Kovacs GG. Prevalence of mixed pathologies in the aging brain. Alzheimers Res Ther. 2014; 6:82.

6. Dolan, D, Troncoso J, Resnick SM, Crain BJ, Zonderman AB, O’Brien RJ Age, Alzheimer's disease and dementia in the Baltimore Longitudinal Study of Ageing. Brain. 2010; 133:2225-2231.

7. Sinka L, Kovari E, Gold G, Hof PR, Herrmann FR, Bouras C, et al. Small vascular and Alzheimer disease-related pathologic determinants of dementia in the oldest-old. J Neuropathol Exp Neurol. 2010; 69:12471255.

8. Strozyk D, Dickson DW, Lipton RB, Katz M, Derby CA, Lee S, et al. Contribution of vascular pathology to the clinical expression of dementia. Neurobiol Aging. 2010; 31:1710-1720.

9. Boyle PA, Wilson RS, Yu L, Barr AM, Honer WG, Schneider JA, et al. Much of late life cognitive decline is not due to common neurodegenerative pathologies. Ann Neurol. 2013; 74:478-489.

10. Kawas CH, Kim RC, Sonnen JA, Bullain SS, Trieu T, Corrada MM. Multiple pathologies are common and related to dementia in the oldest-old: The 90+ Study. Neurology. 2015; 85:535-542.

11. Jellinger KA, Attems J. Prevalence of dementia disorders in the oldestold: an autopsy study. Acta Neuropathol. 2010b; 119:421-433.

12. Wang BW, Lu E, Mackenzie IR, Assaly M, Jacova C, Lee PE, et al. Multiple pathologies are common in Alzheimer patients in clinical trials. Can J Neurol Sci. 2012; 39:592-599.

13. White LR, Edland SD, Hemmy LS, Montine KS, Zarow C, Sonnen, JA, et al. Neuropathologic comorbidity and cognitive impairment in the Nun and Honolulu-Asia Aging Studies. Neurology. 2016;

14. Jellinger KA, Attems J. Challenges of multimorbidity of the aging brain: a critical update. J Neural Transm (Vienna). 2015; 122:505-521.

15. Attems J, Jellinger K. Neuropathological correlates of cerebral multimorbidity. Curr Alzheimer Res. 2013a; 10:569-577.

16. Echavarri C, Burgmans S, Caballero MC, Garcia-Bragado F, Verhey FR, Uylings HB. Co-occurrence of different pathologies in dementia: implications for dementia diagnosis. J Alzheimers Dis. 2012; 30:909917.

17. Attems J, Neltner JH, Nelson PT. Quantitative neuropathological assessment to investigate cerebral multi-morbidity. Alzheimers Res Ther. 2014; 6:85.

18. Chui HC, Ramirez-Gomez L. Clinical and imaging features of mixed Alzheimer and vascular pathologies. Alzheimers Res Ther. 2015; 7:21.

19. Gaugler JE, Ascher-Svanum H, Roth DL, Fafowora T, Siderowf A, Beach TG. Characteristics of patients misdiagnosed with Alzheimer's disease and their medication use: an analysis of the NACC-UDS database. BMC Geriatr. 2013; 13:137.

20. Montine TJ, Phelps CH, Beach TG, Bigio EH, Cairns NJ, Dickson DW, et al. National Institute on Aging-Alzheimer's Association guidelines for the neuropathologic assessment of Alzheimer's disease: a practical approach. Acta Neuropathol. 2012; 123:1-11.

21. Crary JF, Trojanowski JQ, Schneider JA, Abisambra JF, Alafuzoff I, Arnold SE, et al. Primary age-related tauopathy (PART): a common pathology associated with human aging. Acta Neuropathol. 2014; 128:755-766.

22. Kovacs GG. Molecular Pathological Classification of Neurodegenerative Diseases: Turning towards Precision Medicine. Int J Mol Sci. 2016; 17.

23. Kovacs GG, Milenkovic I, Wohrer A, Hoftberger R, Gelpi E, Haberler $\mathrm{C}$, et al. Non-Alzheimer neurodegenerative pathologies and their combinations are more frequent than commonly believed in the elderly brain: a community-based autopsy series. Acta Neuropathol. 2013; 126:365-384.

24. Jellinger KA. Pathology and pathogenesis of vascular cognitive impairment-a critical update. Front Aging Neurosci. 2013; 5:17.

25. Murray ME, Graff-Radford NR, Ross OA, Petersen RC, Duara R, Dickson DW. Neuropathologically defined subtypes of Alzheimer's disease with distinct clinical characteristics: a retrospective study. Lancet Neurol. 2011; 10:785-796.

26. Jellinger KA. Neuropathological subtypes of Alzheimer's disease. Acta Neuropathol. 2012; 123:153-154.

27. Whitwell JL, Dickson DW, Murray ME, Weigand SD, Tosakulwong N, Senjem ML, et al. Neuroimaging correlates of pathologically defined subtypes of Alzheimer's disease: a case-control study. Lancet Neurol. 2012; 11:868-877.

28. Aho L, Parkkinen L, Pirttila T, Alafuzoff I. Systematic appraisal using immunohistochemistry of brain pathology in aged and demented subjects. Dement Geriatr Cogn Disord. 2008; 25:423-432. 
29. Jellinger KA, Attems J. Prevalence and impact of vascular and Alzheimer pathologies in Lewy body disease. Acta Neuropathol. 2008; 115:427-436.

30. Walker L, McAleese KE, Thomas AJ, Johnson M, Martin-Ruiz C, Parker C, et al. Neuropathologically mixed Alzheimer's and Lewy body disease: burden of pathological protein aggregates differs between clinical phenotypes. Acta Neuropathol. 2015; 129:729-748.

31. Frigerio R, Fujishiro $H$, Ahn TB, Josephs KA, Maraganore DM, Delledonne A, et al. Incidental Lewy body disease: Do some cases represent a preclinical stage of dementia with Lewy bodies? Neurobiol Aging. 2011; 32:857-863.

32. Dugger BN, Hentz JG, Adler CH, Sabbagh MN, Shill HA, Jacobson S, et al. Clinicopathological outcomes of prospectively followed normal elderly brain bank volunteers. J Neuropathol Exp Neurol. 2014; 73:244-252.

33. Alafuzoff I, Gelpi E, Al-Sarraj S, Arzberger T, Attems J, Bodi I, et al. The need to unify neuropathological assessments of vascular alterations in the ageing brain. Multicentre survey by the BrainNet Europe consortium. Exp Gerontol. 2012; 47:825-833.

34. Jellinger KA. The pathology of "vascular dementia": a critical update. J Alzheimers Dis. 2008;14:107-123.

35. Ferrer I. Cognitive impairment of vascular origin: neuropathology of cognitive impairment of vascular origin. J Neurol Sci. 2010; 299:139149.

36. Grinberg LT, Thal DR. Vascular pathology in the aged human brain. Acta Neuropathol. 2010; 119:277-290.

37. McAleese KE, Firbank M, Dey M, Colloby SJ, Walker L, Johnson M, et al. Cortical tau load is associated with white matter hyperintensities. Acta Neuropathol Commun. 2015; 3:60.

38. Esiri MM, Englund E. Pathological aspects of the ischemic consequences of small vessel disease on brain parenchyma, In: Pantoni L, Gorelick PB, Editors. Cerebral Small Vessel Disease. Cambridge, UK: Cambridge University Press; 2014. p. 16-28.

39. Attems J, Jellinger KA. The overlap between vascular disease and Alzheimer's disease--lessons from pathology. BMC Med. 2014; 12:206.

40. Esiri MM, Joachim C, Sloan C, Christie S, Agacinski G, Bridges LR, et al. Cerebral subcortical small vessel disease in subjects with pathologically confirmed Alzheimer disease: a clinicopathologic study in the Oxford Project to Investigate Memory and Ageing (OPTIMA). Alzheimer Dis Assoc Disord. 2014; 28:30-35.

41. Toledo JB, Arnold SE, Raible K, Brettschneider J, Xie SX, Grossman M, et al. Contribution of cerebrovascular disease in autopsy confirmed neurodegenerative disease cases in the National Alzheimer's Coordinating Centre. Brain, 2013; 136:2697-2706.

42. Yarchoan M, Xie SX, Kling MA, Toledo JB, Wolk DA, Lee EB, et al Cerebrovascular atherosclerosis correlates with Alzheimer pathology in neurodegenerative dementias. Brain. 2012; 135:3749-3756.

43. Jellinger KA, Attems J. Prevalence and pathology of vascular dementia in the oldest-old. J Alzheimers Dis. 2010a; 21:1283-1298.

44. Jellinger KA. The enigma of mixed dementia. Alzheimer's \& Dementia 2007; 3:40-53

45. Gelber RP, Launer LJ, White LR. The Honolulu-Asia Aging Study: epidemiologic and neuropathologic research on cognitive impairment Curr Alzheimer Res. 2012; 9:664-672.

46. Jellinger KA, Attems J. Neuropathology and general autopsy findings in nondemented aged subjects. Clin Neuropathol. 2012; 31: 87-98.

47. Sonnen JA, Santa Cruz K, Hemmy LS, Woltjer R, Leverenz JB, Montine KS, et al. Ecology of the aging human brain. Arch Neurol. 2011; 68:1049-1056

48. Uchikado H, Lin WL, DeLucia MW, Dickson DW. Alzheimer disease with amygdala Lewy bodies: a distinct form of alpha-synucleinopathy. J Neuropathol Exp Neurol. 2006; 65: 685-697.

49. Savva GM, Wharton SB, Ince PG, Forster G, Matthews FE, Brayne C. Age, neuropathology, and dementia. N Engl J Med. 2009; 360: 23022309.

50. Nelson PT, Alafuzoff I, Bigio EH, Bouras C, Braak H, Cairns NJ, et al. Correlation of Alzheimer disease neuropathologic changes with cognitive status: a review of the literature. J Neuropathol Exp Neurol. 2012; 71:362-381.

51. McAleese KE, Firbank M, Hunter D, Sun L, Hall R, Neal JW, et al Magnetic resonance imaging of fixed post mortem brains reliably reflects subcortical vascular pathology of frontal, parietal and occipital white matter. Neuropathol Appl Neurobiol. 2013; 39:485-497.

52. Braak H, Alafuzoff I, Arzberger T, Kretzschmar H, Del Tredici K. Staging of Alzheimer disease-associated neurofibrillary pathology using paraffin sections and immunocytochemistry. Acta Neuropathol. 2006; 112:389-404.

53. Jicha GA, Abner EL, Schmitt FA, Kryscio RJ, Riley KP, Cooper GE, et al. Preclinical AD Workgroup staging: pathological correlates and potential challenges. Neurobiol Aging. 2012; 33:622 e621-622 e616.

54. Stephan BC, Matthews FE, Ma B, Muniz G, Hunter S, Davis D, et al. Alzheimer and vascular neuropathological changes associated with different cognitive States in a non-demented sample. J Alzheimers Dis. 2012; 29:309-318.

55. Attems J, Jellinger KA. Neuropathology. In: Dening T, Thomas A, Editors. Oxford Textbook of Old Age Psychiatry (2nd ed.). Oxford, UK: Oxford Univ. Press. 2013b. pp 87-105, DOI: 110.1093/med/9780199 644957.9780199644003 .9780199640006$.

56. Clinton LK, Blurton-Jones M, Myczek K, Trojanowski JQ, LaFerla FM. Synergistic interactions between Abeta, tau, and alpha-synuclein: acceleration of neuropathology and cognitive decline. J Neurosci. $2010 ; 30: 7281-7289$.

57. Colom-Cadena M, Gelpi E, Charif S, Belbin O, Blesa R, Marti MJ, et al. Confluence of alpha-synuclein, tau, and beta-amyloid pathologies in dementia with Lewy bodies. J Neuropathol Exp Neurol. 2013; 72:1203-1212. 